\title{
Evaluation of Mandibular Arch Form in A Sudanese Adult Sample With Normal Occlusion
}

Raja Mustafa ( $\sim$ umesra1000@yahoo.com )

Al-Neelain University

Amal Abuaffan

University of Khartoum

\section{Research Article}

Keywords: Mandibular arch form, Dental cast, Sudanese.

Posted Date: December 18th, 2020

DOI: https://doi.org/10.21203/rs.3.rs-128548/v1

License: (c) (1) This work is licensed under a Creative Commons Attribution 4.0 International License. Read Full License 


\section{Abstract}

Background: In fixed orthodontic therapy, maintenance of the original mandibular arch form is considered an essential factor for stability, moreover with the popular use of elastic archwires, and because its shape cannot be easily altered, the pre-determination of mandibular arch form becomes very important for each patient. The purpose of this study is to analyze the mandibular dental arch forms of Sudanese adults with normal occlusion and provides an easy method for orthodontists to determine different types of arch form.

Methods: This Descriptive analytical, cross-sectional study determined the mandibular arch in a sample of 104 Sudanese university students. Measurements were done in the mandibular dental cast. Three arch widths and three arch lengths measurements were established and five ratios were determined. Analysis of arch form was done according to Raberin's polynomial method.

Results: The mid arch form was the most prevalent (75\%), followed by narrow arch form (11.54\%), wide arch form (6.73\%), and pointed arch form (6.73\%). There were no cases in flat arch form.

Conclusions: In Sudanese subjects, four types of arch form were recognized. Norms of transverse and sagittal dimensions of the mandibular arch to determine types of the mandibular arch form in Sudanese orthodontic patients become available.

\section{Background}

The shape of the dental arches has considerable implications in orthodontic diagnosis and treatment planning, affecting the space available, dental esthetics, and stability of the dentition [1]. The Dental arch is initially shaped according to the configuration of the supporting bone and following the eruption of the teeth by the circum-oral musculature and intra-oral functional forces[2, 3].

In contemporary orthodontics for the ease and perfection to the orthodontists, preformed archwires have gained acceptance. Furthermore, with the use of advanced materials, and the use of elastic archwires, it became very important to determine the shape of the mandibular arch form[4].

The stability of orthodontic treatment outcome request no changes in the mandibular arch form [5]. It is known that the mandibular arch has different shapes in different people though each one has normal occlusion. Many factors predispose to differences in mandibular arch form and it is believed that during orthodontic treatment procedures, one must not try to alter the original arch form to have stable results[6]. Orthodontists should select the appropriate shape of archwire for each case separately. some clinicians try to modify archwires for every case, either by using arch guide [7-9], or computer-assisted technique[10]. The arch shape consists of two different areas: the anterior curvature and intercanine width and posterior curvature and intermolar width. A preformed archwire also can be customized for each patient by adjusting the anterior and posterior curvatures [11]. 
The symmetrical curve of dental arches was widely studied by different means. Simple qualitative descriptions were used, as the circular form of the anterior part of the arcade [12,13], tapered, ovoid, and square arch forms $[11,14]$. Also, human dental arch forms have been described using mathematical methods, like Catenary curves [15, 16], and trifocal ellipse [7]. More complex procedures involved different curve-fitting mathematical models were reviewed by many authors. Ferrario et al,[17] evaluated maxillary and mandibular arch by a fourth-order polynomial and mixed model (ellipse and parabola).

Ferrario et al [18] Proved that Euclidean Distance Matrix Analysis (EDMA) is suitable for the analysis in human dental arches. They calculated the center of gravity or centroid of each tooth from cusp tip coordinates and used these points as landmarks later used in the EDMA calculations.

Raberin et al [4] Classify mandibular dental arch into five types (pointed, wide, narrow, mid, flat) based on the k-means clustering method and the use of polynomial functions of the sixth degree.

Dental arch variations exist among different racial groups[19]. Geometric models were anticipated by several authors to identify the mean configuration of the clinical arch shapes in different populations [20]. In a previous study, a comparison of the shape and dimension of the dental arches between African subjects and Caucasian subjects revealed significant differences between the two ethnic samples[21]. So, every population should be managing according to it is characteristics.

Few studies have explored the predominant mandibular arch forms among Sudanese subjects. This study aims to evaluate mandibular dental arch form in Sudanese male and female adults with normal occlusion and to establish a practical mathematical technique, to identify different types of arch form, easy to be available in every orthodontics clinic.

\section{Methods}

This descriptive-analytical, cross-sectional study was carried out in the capital city of the Republic of Sudan (Khartoum), for university students of Al- Neelain University. The students were selected using the following inclusion criteria.

- The subject had to be Sudanese.

- Male and Female aged 16-26 years old.

- The subject had Angle's Class I molar and canine relationship bilaterally.

- Dental arches with well-aligned teeth and space discrepancy of $0 \pm 3 \mathrm{~mm}$.

- Normal overjet and overbite $(2 \mathrm{~mm} \pm 1 \mathrm{~mm})$.

- All teeth were present and fully erupted from the second right molar to the second left molar.

- No history of previous orthodontic treatment.

\section{Sample size:}

The following equation calculated the study sample 
$n=(Z s / e)^{2} \operatorname{deff}$

The sample size was equal to 52 . Therefore, the overall sample became 104 (52 males and 52 females).

\section{Study design:}

A cluster sample technique was used for the selection of faculties. As a result, ten of nineteen faculties of Al Neelain University were selected. Then a simple random method was followed for the selection of students within each chosen faculty.

The study protocol was approved by the Central Institutional Review Board at Al- Neelain University and followed the Declaration of Helsinki Ethical principles for Medical Research Involving Human Subjects. Informed consent was obtained from students who participated in this study. Initial screening for the students was carried out under natural light illumination. The examination was conducted for each student to determine if the participant meets all the inclusion criteria. The examination comprised an intraoral inspection of the teeth and occlusion. For impression taken, Alginate hydrocolloid impression material (ALGINMAX) was mixed according to manufacture. Dental models were poured and prepared with dental stone (OrthoStone).

\section{Measurements:}

Measurements were obtained on mandibular arches. Electronic digital caliper (0-150 mm /6" X0.01 JAPAN) was used to measure the dimensions.

Reference points[4] were determined as; mid-incisal edge on the labial side, canine cusp tips, mesiobuccal cusps of first molars, and distobuccal cusp tips of second molars.

The analysis of dental arches was divided into sex dimensions[4]. Three arch widths and three arch lengths measurements (Figure 1).

The arch breadth (L33) between the canine tips. The mean intermolar width (L66) between the mesiobuccal cusps of the first molars. The posterior intermolar width (L77) between the distobuccal cusps of the second molars. The canine depth (L31) from the mid-incisal edge to the line joining the cusp tips of the canines. The mean arch length (L61) from the mid-incisal edge to the line joining the mesiobuccal cusps of the first molars. The total length (L71) from the incisal edge to the line joining the distobuccal cusps of the second molars.

From these measurements, five ratios[4] (L31/L33, L61/L66, L71/L77, L33/L66, L61/L71) were generated for arch form analysis.

\section{Data analysis}

Data were evaluated using the SPSS (Statistical Package for Social Sciences, Chicago, USA) 20.0 statistical program. The level of significance was set at $p<0.05$. The following tests were used: 
1. Error of method: All measurements were performed by the same researcher. Furthermore, all the variables were measured twice, with a 2-week interval between the two recordings on 25 casts selected at random: intra-observer variability was calculated by using Dahlberg's formula and the measurements obtained ranged between 0.90 and 1.42 .

2. Descriptive analysis including the transverse dimensions, sagittal dimensions, and calculated ratios among the sample.

3. T-test and Fisher's Exact Test were used to evaluate the presence of statistically significant differences between males and females.

\section{Result}

Normal distribution of the data was tested by quantile plots graphical method Fig. 2, as a result, all data were normally distributed.

The mean age of students who participated in this study was $19.5 \pm 2.2 \mathrm{yrs}$. Table 1 shows descriptive statistics for mandibular arch widths and lengths measurements of the total sample.

Table 1

Dimensions (in $\mathrm{mm}$ ) of the mandibular dental arch $(\mathrm{n}=104)$

\begin{tabular}{|lllll|}
\hline Dimensions & Mean & Std. Deviation & Minimum & Maximum \\
\hline Arch width & & & & \\
\hline L 33 & 27.97 & 1.65 & 23.30 & 32.20 \\
\hline L 66 & 46.88 & 2.49 & 40.60 & 53.60 \\
\hline L 77 & 55.46 & 3.16 & 48.50 & 63.10 \\
\hline Arch Length & & & & \\
\hline L 31 & 6.08 & 1.16 & 3.70 & 10.50 \\
\hline L 61 & 25.22 & 1.96 & 19.80 & 29.10 \\
\hline L 71 & 40.92 & 2.62 & 33.60 & 47.90 \\
\hline
\end{tabular}

A Comparison of arch widths and lengths measurements between males and females are shown in Table 2. Arch dimensions were greater in male than female $(p \leq 0.05)$, statistically significant difference was noted in all dimensions except (L31) $p=0.961$ and (L61) $p=0.591$. 
Table 2

Dimensions (in $\mathrm{mm}$ ) of the mandibular dental arch by gender $(\mathrm{n}=104)$

\begin{tabular}{|c|c|c|c|c|c|}
\hline \multirow[b]{2}{*}{ Dimensions } & \multicolumn{2}{|c|}{ Male $(n=52)$} & \multicolumn{2}{|c|}{ Female $(n=52)$} & \multirow[t]{2}{*}{ P-Value } \\
\hline & Mean & Std. Deviation & Mean & Std. Deviation & \\
\hline \multicolumn{6}{|l|}{ Arch width } \\
\hline L 33 & 28.43 & 1.58 & 27.51 & 1.61 & $0.004^{\star}$ \\
\hline L 66 & 48.09 & 2.41 & 45.67 & 1.94 & $<0.001^{*}$ \\
\hline L 77 & 57.08 & 2.98 & 53.84 & 2.43 & $<0.001^{*}$ \\
\hline \multicolumn{6}{|l|}{ Arch Length } \\
\hline L 31 & 6.08 & 1.19 & 6.07 & 1.14 & 0.961 \\
\hline L 61 & 25.32 & 1.95 & 25.12 & 1.98 & 0.591 \\
\hline L 71 & 41.67 & 2.57 & 40.18 & 2.47 & $0.003^{*}$ \\
\hline
\end{tabular}

*Statistically significant

The calculated five ratios of arch form dimensions of the total sample. were shown in Table 3.

Table 3

Mean and SD of the five ratios

\begin{tabular}{|llllll|}
\hline & N & Minimum & Maximum & Mean & Std. Deviation \\
\hline $\mathrm{L} 31 / 33$ & 104 & 0.14 & 0.29 & 0.2142 & 0.03284 \\
\hline $\mathrm{L} 61 / 66$ & 104 & 0.43 & 0.63 & 0.5389 & 0.04330 \\
\hline $\mathrm{L} 71 / 77$ & 104 & 0.61 & 0.88 & 0.7395 & 0.05401 \\
\hline $\mathrm{L} 33 / 66$ & 104 & 0.50 & 0.69 & 0.5973 & 0.03157 \\
\hline $\mathrm{L} 61 / 71$ & 104 & 0.54 & 0.68 & 0.6163 & 0.02757 \\
\hline
\end{tabular}

Determination of arch form for individual case:

Classification of the five types of arch form can be distinguished based on Raberin's[4] method:

Narrow arch form

All sagittal/Transverse ratios (L31/L33, L61/L66, L71/L77) values are higher than average.

Wide arch form

All sagittal/Transverse ratios (L31/L33, L61/L66, L71/L77) values are below average. 


\section{Mid arch form}

None of the ratios deviates from the average

\section{Pointed arch form}

Only the L31/L33 ratio is higher than the average

\section{Flat arch form}

Only the L31/L33 ratio is below the average

The results of the present study showed that $75 \%$ of the Sudanese adults possess mid dental arch form, $11.54 \%$ narrow, $6.73 \%$ wide arch form and, $6.73 \%$ pointe arch form. The flat arch form was not presented. Table 4. The difference in gender distribution was not significant Fisher's Exact Test, $p=0.607$ Table 4 .

Table 4

Distribution of dental arch form in Sudanese sample

\begin{tabular}{|c|c|c|c|c|c|c|c|}
\hline \multirow[t]{2}{*}{ Arch Form Type } & \multicolumn{2}{|c|}{ Female } & \multicolumn{2}{|c|}{ Male } & \multicolumn{2}{|c|}{ Total } & \multirow{2}{*}{$\begin{array}{l}p \text {-value } \\
0.607\end{array}$} \\
\hline & $N$ & $\%$ & $\mathrm{~N}$ & $\%$ & $\mathrm{~N}$ & $\%$ & \\
\hline Mid & 37 & $71.15 \%$ & 41 & $78.84 \%$ & 78 & $75 \%$ & \\
\hline Narrow & 8 & $15.38 \%$ & 4 & $7.70 \%$ & 12 & $11.54 \%$ & \\
\hline Wide & 3 & $5.77 \%$ & 4 & $7.70 \%$ & 7 & $6.73 \%$ & \\
\hline Pointe & 4 & $7.70 \%$ & 3 & $5.77 \%$ & 7 & $6.73 \%$ & \\
\hline Total & 52 & & 52 & & 104 & & \\
\hline
\end{tabular}

\section{Discussion}

This study included young adult subjects, According to growth studies in arch width changes, intercanine and inter-molar widths did not change after 13 years in females and 16 years in males [22, 23], so it was expected that this sample has reached the adult level in arch dimensions.

The present work studied the dimensions of the normal mandibular dental arcade since the mandibular dental arch is considered very important for stability after orthodontics treatment [24].

Measurements in this study were taken from the anatomical points, incisal edges, molars, and canines cusp tips as evaluated by Raberin's et al. [4] According to Raberin's (these points constitute the landmarks that define breaking points of the mandibular arch that limit sectors on which different muscle groups act). Previous literature and studies on dental arch shape used conventional anatomical points on the 
incisal edges and molar cusp tips, etc. to classify dental arch forms using various mathematical forms[5], such as spline curves[25], and the beta function[5]. Despite their clinical impact, conventional anatomic points do not provide clinical evidence of appropriate arch-wire absolute forms. On the contrary, points taken on the vestibular surface of the teeth facial axis give the exact shape of clinical arch-wire[26], as these relate directly to the position of the brackets in orthodontic fixed appliances.

Arch width and Length measurements we observed in our sample, gave higher values in males. In most studies $[4,6,27,28]$, the arch dimensions were smaller in females. Our results are in line with these studies.

Our findings confirm that Sudanese adult with normal occlusion has no single arch form. This agrees with many studies conducted in different populations $[4,6,27,28]$. A comparison was done between Sudanese and other populations in Table 5.

Table 5

Comparison of types of arch form among Sudanese and other racial groups.

\begin{tabular}{|llllll|}
\hline Type of arch form & $\begin{array}{l}\text { Sudanese } \\
\text { Present study }\end{array}$ & $\begin{array}{l}\text { Caucasian } \\
\text { Raberin's } \\
{[4]}\end{array}$ & $\begin{array}{l}\text { Nepalese } \\
{[28]}\end{array}$ & Indian [6] & $\begin{array}{l}\text { Yemeni } \\
{[27]}\end{array}$ \\
\hline Narrow & $11.54 \%$ & 23.7 & 18 & 17.5 & 30.9 \\
\hline Wide & $6.73 \%$ & 19.7 & 24 & 26.4 & 23.9 \\
\hline Mid & $75 \%$ & 18.7 & 13 & 22.8 & 9.3 \\
\hline Pointe & $6.73 \%$ & 19.4 & 19 & 15.8 & 17.6 \\
\hline Flat & $0 \%$ & 18.3 & 26 & 17.5 & 18.3 \\
\hline Total & 104 & 278 & 100 & 57 & 398 \\
\hline
\end{tabular}

Mid arch form type was the most predominant in the Sudanese sample. Narrow arch form type is predominant in Caucasian[4] and Yemeni [27] samples. Flat arch form types are predominant in Nepalese [28]. Wide arch form types are predominant in Gujarati[6]. This finding may be related to the fact that dissimilar populations show the different distribution in types of arch form.

This study provides norms for mandibular transverse and sagittal dimensions, that could be applied by an easy method to classify different forms of mandibular arch in Sudanese orthodontics patients Fig. 3.

\section{Conclusion}

Based on the results of the present study, the following conclusions can be drawn:

- In Sudanese adults, the mid arch form is the most predominant arch form. 
- Arch form types were not associated with gender.

- A Guide for classification of mandibular arch form in Sudanese orthodontics patients become available.

\section{Abbreviations}

L33: Inter-canine width, L66: Mean inter-molar width,

L77: Posterior inter-molar width, L31: Canine depth

L61: Mean arch length, L71: Total length

SD: Standard deviation, N: Number

\section{Declarations}

\section{Ethics approval and consent to participate}

This study was approved by the Central Institutional Review Board at Al- Neelain University, and followed the Declaration of Helsinki Ethical principles for Medical Research Involving Human Subjects.

Participation in the study was voluntary. Informed consent was obtained from students who participated in this study and from Deans of the faculties for those participants under the age of 18 years.

\section{Consent for publication}

Not applicable.

\section{Availability of data and materials}

The data that support the findings of this study are available on reasonable request from the corresponding author. The data are not publicly available due to privacy.

\section{Competing interests}

We declare no conflicts of interest.

\section{Funding}

Nil

\section{Authors contributions:}

Raja AG. Mustafa was responsible for the study concept and design; data acquisition and preparation of the manuscript. 
Amal H. Abuaffan was the main supervisor for this research. All authors read and approved the final manuscript.

\section{Acknowledgments}

We would like to thank all students that participate in this study for their nice cooperation during data collection.

\section{Author information}

\begin{tabular}{|c|c|c|c|c|}
\hline $\begin{array}{l}\text { S. } \\
\text { No. }\end{array}$ & Name & Department & University & Degree \\
\hline \multirow[t]{4}{*}{$1-$} & \multirow{4}{*}{$\begin{array}{l}\text { Raja Abd } \\
\text { Algadir } \\
\text { Mustafa }\end{array}$} & \multirow[t]{4}{*}{ Orthodontic department } & \multirow{4}{*}{$\begin{array}{l}\text { Al } \\
\text { Neelain } \\
\text { University }\end{array}$} & Lecturer Al Neelain University \\
\hline & & & & $\begin{array}{l}\text { MSc. (Orthodontics) University of } \\
\text { Khartoum }\end{array}$ \\
\hline & & & & B.D.S University of Khartoum \\
\hline & & & & $\begin{array}{l}\text { ORCID ID: https://orcid.org/0000- } \\
\text { 0001-9928-600X }\end{array}$ \\
\hline \multirow[t]{4}{*}{ 2- } & \multirow{4}{*}{$\begin{array}{l}\text { Amal } \\
\text { Hussein } \\
\text { Abuaffan }\end{array}$} & \multirow{4}{*}{$\begin{array}{l}\text { Department of } \\
\text { orthodontics, Pedodontics } \\
\text { and preventive dentistry }\end{array}$} & \multirow{4}{*}{$\begin{array}{l}\text { University } \\
\text { of } \\
\text { Khartoum }\end{array}$} & Professor University of Khartoum \\
\hline & & & & $\begin{array}{l}\text { MSc. (Orthodontics) University of } \\
\text { Bergen }\end{array}$ \\
\hline & & & & B.D.S University of Khartoum \\
\hline & & & & $\begin{array}{l}\text { ORCID ID: https://orcid.org/0000- } \\
0001-7014-4147 \\
\text { https://orcid.org/0000-0001-7014- } \\
4147\end{array}$ \\
\hline
\end{tabular}

\section{Corresponding author}

Name: Raja Abd Algadir Mustafa

Department: Orthodontic department

University: Al Neelain University

Address: Khartoum, Sudan

Telephone: +249912460182

E mail: umesra1000@yahoo.com

\section{References}


1. Lee RT. Arch width and form: a review. American Journal of Orthodontics and Dentofacial Orthopedics. 1999;115(3):305-13.

2. Mohammad H, Hassan MA, Hussain S. Dental arch dimension of Malay ethnic group. American Journal of Applied Sciences. 2011;8(11):1061-6.

3. Triviño T, Siqueira DF, Scanavini MAJAJoO, Orthopedics D. A new concept of mandibular dental arch forms with normal occlusion. 2008;133(1):10. e5-. e22.

4. Raberin M, Laumon B, Martin J-L, Brunner F. Dimensions and form of dental arches in subjects with normal occlusions. American Journal of Orthodontics and Dentofacial Orthopedics. 1993;104(1):6772.

5. Bondemark L, Holm A-K, Hansen K, Axelsson S, Mohlin B, Brattstrom V, et al. Long-term stability of orthodontic treatment and patient satisfaction: a systematic review. The Angle orthodontist. 2007;77(1):181-91.

6. Patel VJ, Bhatia AF, Mahadevia SM, Italia S, Vaghamsi M. Dental arch form analysis in Gujarati males and females having normal occlusion. Journal of Indian Orthodontic Society. 2012;46(6):295-9.

7. Brader AC. Dental arch form related with intraoral forces: $P R=C$. American Journal of Orthodontics and Dentofacial Orthopedics. 1972;61(6):541-61.

8. Pandis N, Polychronopoulou A, Eliades T. Self-ligating vs conventional brackets in the treatment of mandibular crowding: a prospective clinical trial of treatment duration and dental effects. American Journal of Orthodontics and Dentofacial Orthopedics. 2007;132(2):208-15.

9. Lisniewska-Machorowska B, Cannon J, Williams S, Bantleon H-P. Evaluation of force systems from a "free-end" force system. American Journal of Orthodontics and Dentofacial Orthopedics. 2008;133(6):791. e1-. e10.

10. Taner TU, Ciğer S, El H, Germec D, Es A. Evaluation of dental arch width and form changes after orthodontic treatment and retention with a new computerized method. American Journal of Orthodontics and Dentofacial Orthopedics. 2004;126(4):463-74.

11. Slaj M, Spalj S, Jelusic D, Slaj MJAjoo, orthopedics d. Discriminant factor analysis of dental arch dimensions with 3-dimensional virtual models. 2011;140(5):680-7.

12. Boone GN. Archwires designed for individual patients. The Angle orthodontist. 1963;33(3):178-85.

13. Rudge S. Dental arch analysis: arch form A review of the literature. The European Journal of Orthodontics. 1981;3(4):279-84.

14. Bishara SE, Saunders W. Textbook of orthodontics: Saunders Book Company; 2001.

15. Musich DR, Ackerman JL. The catenometer: a reliable device for estimating dental arch perimeter. American Journal of Orthodontics and Dentofacial Orthopedics. 1973;63(4):366-75.

16. McConal M, Scher E. Ideal form of the human dental arcade with some prosthetic appliance. 1949.

17. Ferrario VF, Sforza C, Miani Jr A, Tartaglia G. Mathematical definition of the shape of dental arches in human permanent healthy dentitions. The European Journal of Orthodontics. 1994;16(4):287-94. 
18. Ferrario VF, Sforza C, Miani Jr A, Tartaglia G. Human dental arch shape evaluated by Euclideandistance matrix analysis. American journal of physical anthropology. 1993;90(4):445-53.

19. Aitchison J. Some racial contrasts in teeth and dental arches. Dent Mag Oral Top. 1965;82(5):20115.

20. Collins BP, Harris EJTJotTDA. Arch form in American blacks and whites with malocclusions. 1998;78(1):15.

21. Lombardo L, Coppola P, Siciliani GJlo. Comparison of dental and alveolar arch forms between different ethnic groups. 2015;13(4):462-88.

22. Golwalkar SA, Msitry KA. An evaluation of dental crowding in relation to the mesiodistal crown widths and arch dimensions. Journal of Indian Orthodontic Society. 2009;43(2):22.

23. Bishara SE, Ortho D, Jakobsen JR, Treder J, Nowak A. Arch width changes from 6 weeks to 45 years of age. American Journal of Orthodontics and Dentofacial Orthopedics. 1997;111(4):401-9.

24. Little RM, Wallen TR, Riedel RA. Stability and relapse of mandibular anterior alignment-first premolar extraction cases treated by traditional edgewise orthodontics. American Journal of Orthodontics and Dentofacial Orthopedics. 1981;80(4):349-65.

25. Braun S, Hnat WP, Fender DE, Legan HL. The form of the human dental arch. The Angle orthodontist. 1998;68(1):29-36.

26. AlHarbi S, Alkofide EA, AlMadi A. Mathematical analyses of dental arch curvature in normal occlusion. The Angle orthodontist. 2008;78(2):281-7.

27. Al-Zubair NM. Establishment of Yemeni dental arch form. Orthodontic journal of Nepal. 2013;3(2):22-6.

28. Shrestha RM. Polynomial analysis of dental arch form of Nepalese adult subjects. Orthodontic journal of Nepal. 2013;3(1):7-13.

\section{Figures}




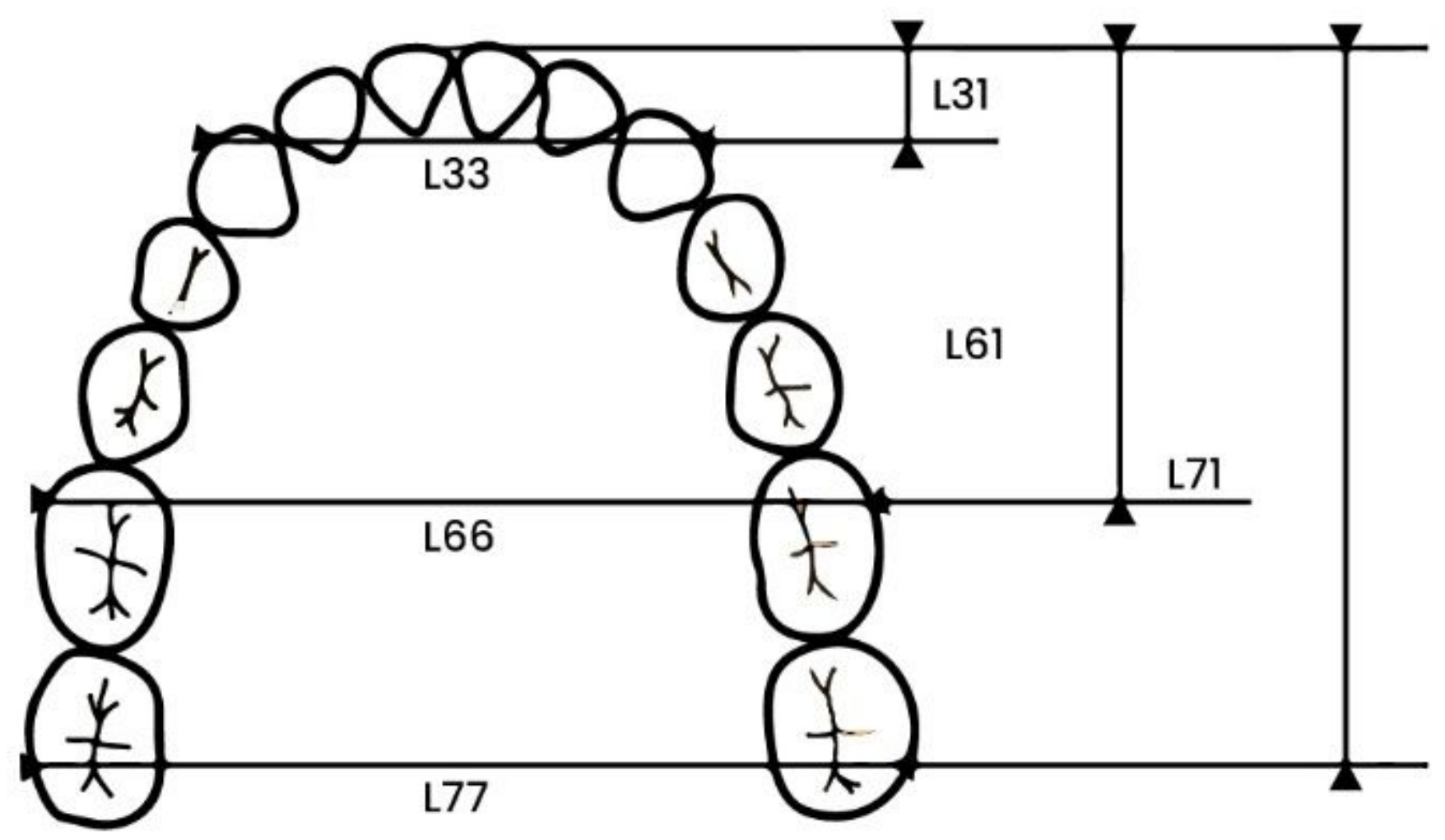

Figure 1

Arch width and Length measurements in the mandibular cast 


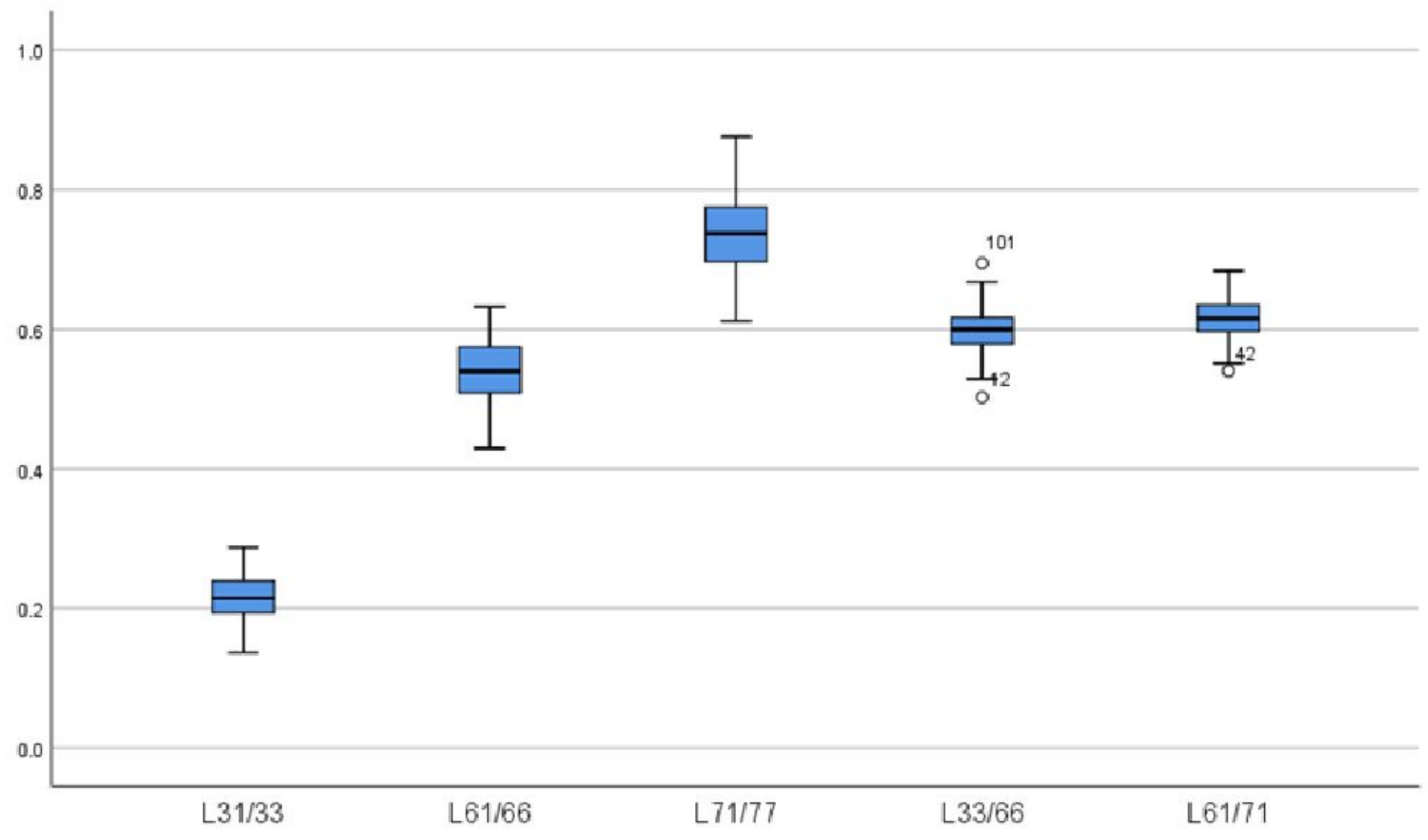

Figure 2

quantile plots a graphical method for the normal distribution of the data. 


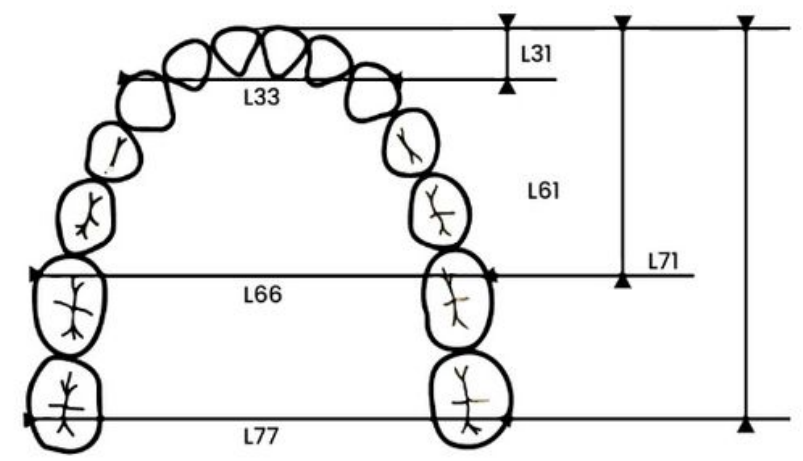

L33: Inter-canine width

L66: Mean inter-molar width

L77: Posterior inter-molar width

L31: Canine depth

L61: Mean arch length

L71: Total length

\begin{tabular}{|c|l|}
\hline Ratios & Average \\
\hline $\mathbf{L} 33 / 31$ & $0.24-0.11$ \\
\hline $\mathbf{L 6 6 / 6 1}$ & $0.58-0.49$ \\
\hline $\mathbf{L 7 7 / 7 1}$ & $0.79-0.68$ \\
\hline
\end{tabular}

Classification of mandibular arch form ${ }^{[1]}$

Narrow arch form: All (L31/L33, L6I/L66, $\mathrm{L} 7 \mathrm{l} / \mathrm{L} 77)$ values are above average.

Wide arch form: All (L31/L33, L6I/L66, $\mathrm{L} 7 \mathrm{~L} / \mathrm{L} 77)$ values are below average.

Mid arch form: None of the ratios deviates from the average.

Pointed arch form: Only the L31/L33 ratio is above average.

Flat arch form: Only the L31/L33 ratio is below average

\section{Figure 3}

Guide for classification of mandibular arch form in Sudanese orthodontics patient 